\title{
Tangible User Interface Design for Home Automation Energy Management Appliances
}

\author{
Miji Park* \\ Seoul National University
}

\author{
Juhyun Eune ${ }^{\dagger}$ \\ Seoul National University
}

\author{
Suzung Kim ${ }^{\ddagger}$ \\ Seoul National University
}

Keywords: Tangibility, Interaction, Home Automation

\section{INTRODUCTION}

Home Automation System connects the digital technology and computers to the appliances at home and manages it. It's the frequency of use an position in the home that makes it important to have an aesthetic friendly user interface. There are numerous UI design cases of Display panel or the buttons. However, the usability or aesthetic sensibility design through using a variety of multi-layered emotional satisfaction of feeling that provides the interface design needs to be studied. This study explores the ways to satisfy the emotional needs of Home Automation System and Tangible User Interface (TUI).

\section{CONCEPT}

Appono is an energy management appliance that controls all of air, water, and lighting in a home automation environment. Appono stands for set in Latin and it shows very interesting and direct user experience through tangible operation unit which resembles the shape of pebbles. Instead of the old innovative control system with unorganized and complicated menu structure and user flow, this study improved the interface design.
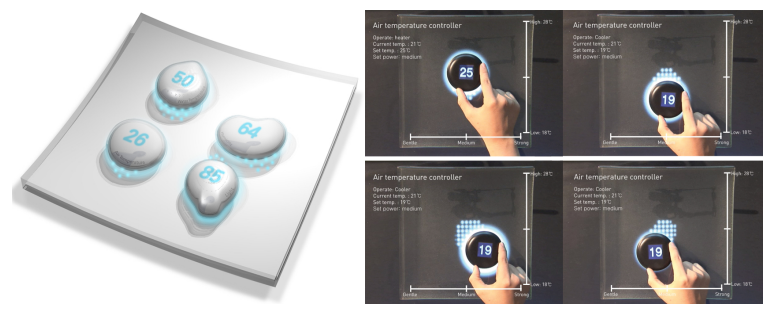

Figure 1: 3D Modelling and Prototype Installation of Appono

\section{METHODOLOGY}

The operation unit is composed of four units (air-conditioning, humidity, water temperature, and lighting) and each unit is control separately. The main operating method is as follows: 1. Operation units have their own icon that symbolizes each function. 2. Users are able to turn On and Off easily by putting units on plate. 3. Each unit has their own coordinates so the user can control set point and mode by changing them. 4. Users are able to set timer on each system. As time lever of Analogue are turned the timer is set up.

The Interface operated by gesture base. And It feeds visual signs back. Gesture for Controlling Fungtion and Display Elements are as follows: 1. On: Put the Unit on the Plate. 2. Off: Put the Unit down. 3. Changes Setting:Push the Unit following cordinate. 4.

\footnotetext{
*e-mail: mizipark@gmail.com

†e-mail: jheune@snu.ac.kr

‡e-mail: suzung@snu.ac.kr
}

Changes Midpoint:Carry up the Unit on the Plate . 5. Changes Timer Setting:Turn the Unit following gradation on the Plate.

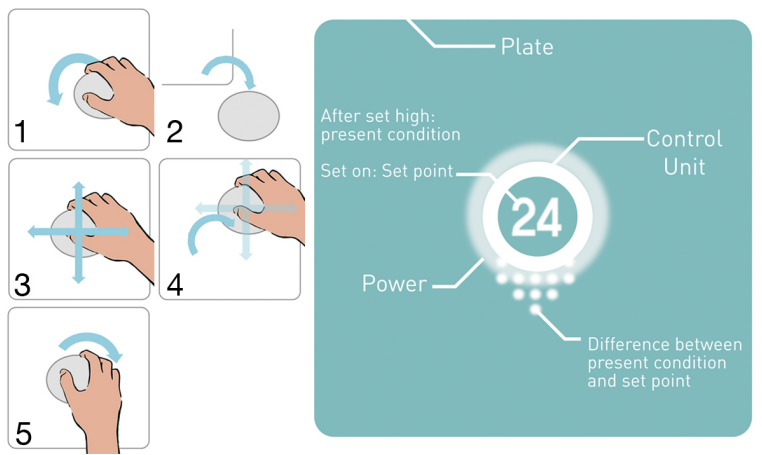

Figure 2: Gesture for Controlling Fungtion and Display Elements

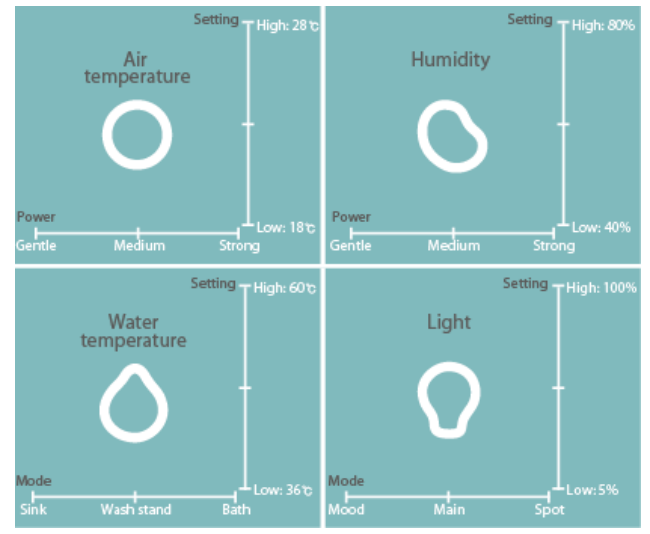

Figure 3: Setting Coordinate of each Unit's Function

[For example] Air temperature operating method

1. When users put units on plates, control system is On. 2. When Y axis goes up, temperature rises. When $\mathrm{Y}$ axis goes down, temperature falls. 3. When $X$ axis goes up, it is strong wind, when $X$ axis goes down, it is moderate wind. 4 . When users turn units, the timer turns and begins to count time. When counting finishes, system stops. 5. Also, system stops even the units are off from plates.

When the user changes settings, Appono transmits the new set points to the home automation middle control server. Then, airconditioning, Boiler, humidifier, dehumidifier, and lighting system adjust as what server tells. Meanwhile, Appono shows directly the difference between set point and present conditions to users. The difference appears by moving points.

\section{REFERENCES}

Ben Shneiderman, Catherine Plaisant, Designing the user interface, Pearson, 2010

Diana $\mathrm{Xu}$, Designing and Testing a Tangible Interface Prototype, IDC, 2007 